\title{
Reserve Volatility and the Identification of Exchange Rate Regimes
}

\author{
Michael Bleaney ${ }^{1}$ (D) Mo $\operatorname{Tian}^{2}$
}

Accepted: 20 January 2021 / Published online: 18 February 2021

(C) The Author(s) 2021

\begin{abstract}
Should exchange rate regime classifications be based purely on some measure of exchange rate flexibility, or should such flexibility be judged in proportion to the degree of exchange market pressure (EMP), as reflected in the behaviour of international reserves? Some authors have claimed that the best approach to classifying exchange rate regimes is to estimate to what extent EMP is absorbed in reserve variability rather than exchange rate variability. Empirical evidence is presented on the variability of reserves and exchange rates for 193 countries from 1980 to 2019. Pegged regimes do not display any more reserve volatility than floats. In most regimes there is a small but statistically significant positive correlation between reserve accumulation and exchange rate appreciation in monthly data, but this effect is no stronger in less flexible regimes, where intervention is expected to be greater. A flexibility index is constructed, based on the ratio of exchange rate flexibility to reserve volatility, and is compared to one based solely on exchange rate flexibility by investigating its conformity with the IMF de facto classification. The flexibility index that takes reserves into account does not improve the identification of pegs, but it helps to a limited extent to distinguish free floats from managed floats.
\end{abstract}

Keywords Exchange rates regimes - Exchange rate band - Exchange market pressure, international reserves

JEL F31

Michael Bleaney

michael.bleaney@nottingham.ac.uk

Mo Tian

mo.tian@nottingham.ac.uk

1 School of Economics, University of Nottingham, Nottingham, England

2 Business School, University of Nottingham, Nottingham, England 


\section{Introduction}

Exchange rate classification schemes are usually based exclusively on the behaviour of the exchange rate, at least in distinguishing some form of peg or band from a (possibly managed) float (e.g. Bleaney and Tian 2017; Ilzetzki et al. 2017; Shambaugh 2004; see Tavlas et al. 2008, for a survey). However, some authors have argued that such classifications should take account of movements in international reserves as well as in exchange rates. Frankel and Wei $(2008$, p. 7) condemn "...the folly of judging a country's exchange rate regime by looking simply at variation in the exchange rate" and they go on to say: "One must focus on exchange rate variability relative to reserve variability to gauge where a country sits on the spectrum of fixed to floating." A similar assertion of the necessity of a multi-dimensional approach to exchange rate regime classification appears in Levy-Yeyati and Sturzenegger (2005, p.1608). An alternative view to this, the rationale for which we discuss below, is that exchange rate dynamics are sufficient to define a peg, but that reserve variability may be relevant in distinguishing between floating exchange rates that are allowed to move more or less freely from those that are tightly managed.

The argument for a multi-dimensional approach draws on the extensive literature on exchange market pressure (Girton and Roper 1977; Weymark 1995), which recognises that, in the event of excess demand (supply) for the domestic currency at the current exchange rate, the government must either soak it up by accumulating (spending) reserves or by reducing (raising) interest rates, or allow the currency to appreciate (depreciate). Exchange market pressure in its most basic form is measured as the sum of the percentage exchange rate appreciation (usually relative to the US dollar) and the percentage increase in international reserves. This may be refined by some combination of (a) normalisation of the components of EMP by subtracting the sample mean and dividing by the sample standard deviation and/or (b) adding in the change in interest rate differentials (foreign minus domestic) (Aizenman et al. 2012; Aizenman and Binici 2016). Other approaches to measuring EMP are discussed by Hall et al. (2013) and Patnaik et al. (2017). Factors that may cause reserves to change in value without intervention, such as valuation changes and interest payments, are implicitly treated as a minor problem, even though they may be a significant distortion when intervention is rare (Patnaik et al. 2017, p. 65).

In this paper we address the question of whether reserve volatility is higher under pegs, so that taking it into account helps us to distinguish pegs from floats. If reserve volatility were not higher under pegs, then the observation that pegs tend to have a lower ratio of exchange rate flexibility to reserve volatility would derive entirely from the exchange rate element, and observers would be justified in ignoring reserve volatility in identifying pegs. This issue has not usually been explicitly addressed; instead, proponents of particular classification schemes have tended to answer it only implicitly, by either taking some account of reserve volatility or ignoring it completely in defining a peg (see Tavlas et al. 2008, for a survey). We find that reserve volatility is not, in general, any greater under pegs, and therefore it does not help in distinguishing pegs from floats. We then consider whether reserve volatility is of use in identifying how tightly a float is managed.

The paper is structured as follows. Section Two surveys the criteria used to distinguish a peg from a float in various exchange rate classification systems. Section Three introduces the measure of exchange rate flexibility. Preliminary issues 
are discussed in Section Four, and our main results are presented in Section Five. Section Six concludes.

\section{Exchange Rate Regime Classifications}

Most analyses of exchange rate regimes end up with a limited number of categories, such as "Pegs", "Intermediate Regimes" and "Floats", which may or may not be further disaggregated.

Some classifications use cluster analysis to identify combinations of low exchange rate volatility and high reserve volatility (Levy-Yeyati and Sturzenegger 2005, 2016; Strelchenko 2018). We might term this "the EMP approach" to exchange rate classification. The rationale for this is that governments dislike both exchange rate volatility and reserve volatility, and as EMP increases, they will tend to choose a bit more of each; but if governments vary considerably in the strength of their desires for stability of exchange rates rather than reserves, in a cross-country sample there will be substantial variation in the ratio of exchange rate volatility to reserve volatility, and this information may be used to identify their preferences.

On the other hand, many exchange rate classification schemes ignore reserve volatility altogether in defining a peg, without attracting widespread criticism. Shambaugh (2004) defines a calendar year where there is a narrow range of variation of the exchange rate against some anchor currency of $\pm 2 \%$ in any month, or one where there is no change at all in eleven of the twelve months, as a peg. Anything else is defined as a non-peg. Obstfeld et al. (2010) allow for a softer category of peg as well, with permitted variation of $\pm 5 \%$. Reinhart and Rogoff (2004), updated in Ilzetzki et al. (2017), define a peg or a band based on monthly exchange rate changes in rolling five-year periods. For pegs, $80 \%$ of the observations must fall in a range of $\pm 1 \%$ ( $\pm 5 \%$ for bands). The IMF classification allows for basket pegs and crawling pegs and bands, and has evolved over time (for details, see Habermeier et al. 2009), but it has always just been based on exchange rate behaviour and has never included information about reserves.

One can justify this approach in EMP terms on the following grounds. Once a government announces a peg with well-defined limits of variation, it creates a large discontinuity in the marginal cost function of exchange rate volatility. So long as exchange rate volatility is low enough to keep the rate within the limits, the cost of any additional volatility is virtually zero, but as soon as those limits are breached, the policy fails and the cost of any additional volatility becomes very large. Consequently there is a sharp discontinuity in the marginal cost function of exchange rate volatility, which has the effect that over a wide range of levels of EMP, extra EMP is almost entirely absorbed in reserve volatility in order to keep exchange rate volatility below this threshold. If EMP is only relatively rarely large enough to cause a parity change, most pegs will be characterised by low exchange rate volatility but highly variable reserve volatility. ${ }^{1}$ In other words the basic premise of the EMP approach - that

\footnotetext{
${ }^{1}$ For evidence of the skewed distribution of estimates of EMP in the cases of particular currencies, with large absolute values being relatively rare, see for example Hall et al. (2013, Figs 1-3) or Patnaik et al. (2017, Fig. 1). Two reasons why EMP is rarely high could be: (1) that many pegs have high credibility; and (2) even without this, speculators face a co-ordination problem in judging when an attack might be successful, and may therefore be hesitant to incur the costs of attacking a currency even when they regard it as misaligned.
} 
governments wish to trade off exchange rate volatility against reserve volatility - may be correct, but the discontinuity in the marginal cost function associated with an exchange rate peg renders reserve volatility unhelpful in identifying a peg. By the same token, however, if we consider a floating exchange rate, there is no such discontinuity, and a greater preference for exchange rate stability should be reflected in greater reserve volatility (or other measures designed to manage the exchange rate). Therefore reserve volatility may well be useful in distinguishing tightly managed floats from ones that are very loosely managed, if at all.

\section{A Measure of Exchange Rate Flexibility}

To compare an exchange rate classification system based purely on exchange rates with one that also uses data on reserves, a continuous measure of exchange rate flexibility is required. Bleaney and Tian (2017) suggest one that allows for all types of pegs (basket pegs, crawling pegs) and for the occasional parity change, as does the IMF classification. Their method is based on a regression similar to that previously used by Frankel and Wei (1995) and Slavov (2013) to identify the basket of anchor currencies for a pegged regime. The principle is that the movement of any currency $\mathrm{X}$ against a numeraire currency $\mathrm{N}$ will track closely the movement of other currencies $\mathrm{A}, \mathrm{B}, \mathrm{C}$ etc. against $\mathrm{N}$ if $\mathrm{X}$ is pegged to one or a weighted average of these currencies, so that this regression will be characterised by a low root mean square error (RMSE). If currency $\mathrm{X}$ is floating, the fit of this regression will be much poorer. Consequently this RMSE may be regarded as an indicator of exchange rate flexibility. End-of-month observations are used to generate a flexibility measure for each calendar year, with the Swiss franc as numeraire (Bleaney and Tian 2017) or, in the further analysis of Bleaney and Tian (2020), with the Japanese yen as numeraire. The flexibility index is designed to be comprehensive, in that it caters for a single parity change with the exchange rate pegged before and after the change, and for crawling pegs as well as horizontal pegs. The sample consists of 193 countries over the years 1980 to 2019.

Since the number of degrees of freedom in the regression is limited when only twelve observations are used, there is an issue of whether the accuracy of the measure can be improved by extending the number of months, although there is a trade-off here with the increased risk of a distortion of the measure by a regime change occurring during the period. For the sake of robustness, we present results for 18-month and 24month regressions as well.

Although Bleaney and Tian (2017) have suggested an RMSE of below 0.01 as a suitable criterion for a peg, the majority of pegs are much tighter than this, with an RMSE of less than 0.001, which we label "Tight Pegs". We examine whether there are any systematic differences between Tight Pegs and Loose Pegs (i.e. those with an RMSE between 0.001 and 0.01 ); in particular we show that Tight Pegs are virtually $100 \%$ single-currency pegs, whereas Loose Pegs are not.

The analysis here is based on using the Japanese yen as the numeraire. The potential anchor currencies that we consider are the US dollar and the euro, but with others added in particular cases as listed in Bleaney and Tian (2017, p. 304). Up to 1998, when the euro had not yet been created, we use the German mark and the French franc instead. The regression relates exchange rate movements of currency $i$ against the chosen 
numeraire currency $N$ (in this case the Japanese yen) to movements of potential anchor currencies against $N$ :

$$
\Delta \ln E(i, N)_{t}=a+b \Delta \ln E(U S D, N)_{t}+c \Delta \ln E(E U R, N)_{t}+u_{t}
$$

where USD is the US dollar, EUR is the euro, $E(i, N)$ is the number of units of currency $i$ per yen (so an increase represents a depreciation of currency $i$ ), and $\Delta$ is the firstdifference operator. In a single-currency peg to the euro, the euro-yen exchange rate should have a coefficient equal to one, and any other exchange rate should have a coefficient of zero. In a basket peg, the coefficients of the currencies making up the basket should sum to one. If the government operates a crawling peg, with a steady devaluation rate of $x \%$ per month, the value of $x$ can be estimated from the intercept term in the regression.

Where this regression covers the twelve months of a calendar year, as in Bleaney and Tian $(2017,2020)$, the precise procedure is as follows. The classification is based on the root mean square error (RMSE) of this regression, which we shall call Regression A. To allow for the possibility of one parity change per year, Bleaney and Tian (2017) estimate 12 extra regressions, each with a dummy variable equal to one in one month only added to Regression A. Call these regressions $\mathrm{B}(1)$ to $\mathrm{B}(12)$. If none of the dummy variables is statistically significant enough, Regressions $B(1)$ to $B(12)$ are ignored, and that country-year is coded a Fix if RMSE $<0.01$, and a Float otherwise. If any of the dummy variables is significant enough, the B regression with the most significant dummy variable becomes the focus of attention. ${ }^{2}$ If the RMSE $<0.01$ in the chosen B regression, that country-year is coded as a Peg with a Parity Change, and otherwise a Float. We impose two exceptions to this rule, however. (1) If the estimated parity change is very small $(< \pm 0.02)$, we treat it as a movement within an unchanged band rather than a shift in the central rate, and the observation is coded a Fix. (2) Since revaluations are in practice rare, except where one is known to have occurred, if the estimated parity change is a revaluation of $>0.02$, this is assumed to be spurious, and the $\mathrm{B}$ regressions are ignored, the coding instead being based on Regression $\mathrm{A}{ }^{3}$ This classification is available up to 2019 .

\section{3Some Preliminary Issues}

\subsection{The Time Span of the Regression}

In choosing the time span of the regression used for measuring exchange rate flexibility, there is clearly a trade-off between accuracy and the possibility of regime change. With a longer time span, the regression has more degrees of freedom, but it is more likely that there has been a regime change during the period. To address this issue we consider regressions of length 18 and 24 months as well as twelve months, with the

\footnotetext{
${ }^{2}$ Bleaney and Tian (2017) suggest an F-statistic $>30$ for the addition of the dummy variable as the critical value.

${ }^{3}$ We treat Germany 1983 and China 2005 as genuine parity changes.
} 
number of B regressions estimated being correspondingly increased. To be absolutely clear, the RMSE attributed to the year 2019 is based on January to December 2019 in the 12-month case, July 2018 to December 2019 in the 18-month case, and January 2018 to December 2019 in the 24-month case.

When applied on a 12-month basis for a calendar year, as in Bleaney and Tian (2017, 2020), the degrees of freedom in this regression are nine in the case where no parity change is identified (twelve observations and three regressors), and only eight when there is a parity change. This is reduced further in the small number of cases when potential anchor currencies other than the US dollar and the euro are added. It is possible that this small number of degrees of freedom biases the estimated RMSE downwards (since as the degrees of freedom approach zero, so does the RMSE). It is also likely that the volatility of a floating currency varies considerably from year to year, and that a more consistent estimate would be obtained from a longer regression. On the other hand, a regime switch during the period biases the measure upwards (Bleaney and Tian 2020), and a longer regression increases the chance of a regime switch.

To address this issue, we compare the results for different regression lengths for a number of currencies. Table 1 show some statistics for six currencies that were known to be freely floating in the years 2000 to 2019 , so there is no regime change issue. For each country, the RMSE from eq. (1) is shown for a regression of 12 months (January of year T to December of year T), eighteen months (July of year T-1 to December of year T) and 24 months (January of year T-1 to December of year T). Table 1 provides the mean RMSE for each country over these twenty years, together with its standard deviation.

Table 1 The effects of the regression span on the RMSE for selected countries 2000 to 2019

\begin{tabular}{llll}
\hline Country & 24 months & 18 months & 12 months \\
\hline United States & & Mean & 1.93 \\
United Kingdom & 2.03 & 2.05 & 1.75 \\
Canada & 1.75 & 1.74 & 2.07 \\
Japan & 2.13 & 2.12 & 2.20 \\
Australia & 2.27 & 2.25 & 2.27 \\
New Zealand & 2.35 & 2.27 & 2.64 \\
& 2.74 & 2.66 & 0.600 \\
United States & & Standard Deviation & 0.659 \\
United Kingdom & 0.507 & 0.546 & 0.733 \\
Canada & 0.525 & 0.641 & 0.885 \\
Japan & 0.630 & 0.651 & 0.732 \\
Australia & 0.644 & 0.718 & 0.910 \\
New Zealand & 0.417 & 0.510 & 0.622 \\
\hline
\end{tabular}

The statistics are the mean and standard deviations of the RMSEs, both multiplied by 100, for the years 2000 to 2019 derived from estimating Eq. (1) over 24-month, 18-month and 12-month horizons, as described in the text 
The mean shows a slight tendency to increase, the maximum being about $5 \%$, between the 12-month regression and the 24-month one. This suggests that the downward bias from the relatively small degrees of freedom in the 12-month regression is quite limited. On the other hand, the differences in standard deviations are much more marked. The reduction in the standard deviation in the 24-month regression compared with the 12-month regression is about $14 \%$ for Canada, about $15 \%$ for the US and the UK, and more than 25\% for Japan, Australia and New Zealand. This provides a strong indication that a longer regression is better, in the sense of producing more consistent results from period to period, so long as one can be sure that the regime has not changed during the period.

\subsection{Tight and Loose Pegs}

Although we have suggested that an RMSE of less than 0.01 should define a peg, there is a considerable preponderance of pegs with very small RMSEs $(<0.001)$. In this section we investigate whether these Tight Pegs, as we label them, tend to be significantly different from Loose Pegs (RMSE between 0.001 and 0.01). For instance, are they more likely to be single-currency pegs? This seems likely to be the case because of the transparency of a single-currency peg (it is extremely easy for agents to check whether the announced regime is being adhered to), and also because Loose Pegs may include heavily managed floats that aim only to keep the exchange rate within a certain range, as well as committed peggers.

Figure 1 shows the cumulative distribution function of the size of the largest exchange rate coefficient in each regression for Tight and Loose Pegs separately. In most cases this is just the larger of the euro and US dollar coefficients. For singlecurrency pegs, this statistic should be very close to one, whereas for basket pegs or for floats that are very tightly managed it will tend to be rather smaller, because of the weight attached to other currencies. In Fig. 1, the percentile is on the vertical axis and the statistic is on the horizontal axis. For Tight Pegs (1901 cases), the cumulative distribution is very close to being a vertical line at one, indicating virtually $100 \%$ single-currency pegs. For Loose Pegs (1850 cases), the picture is much more varied: the 25 th percentile is 0.647 , and the 50th percentile is 0.921 , which suggests that only about half of Loose Pegs are single-currency pegs or something very close to it. ${ }^{4}$

\section{The Volatility of International Reserves and the Exchange Rate Regime}

There has been little empirical examination of the relationship between the variability of reserves and of exchange rates, and the overall picture is unclear. Calvo and Reinhart (2002, Fig. 1) focus on the proportion of months in which reserves increase or decrease by more than $2.5 \%$, and find that this proportion is much the same over different types of exchange rate regime in a sample of 39 countries from January 1970 to November 1999. They interpret this as widespread "fear of floating" (i.e. fear of an independent

\footnotetext{
${ }^{4}$ The figures are based on the 24-month regressions (results for 18 months and 12 months are very similar). Currency unions are counted once only. For more data, see Appendix Table 9.
} 


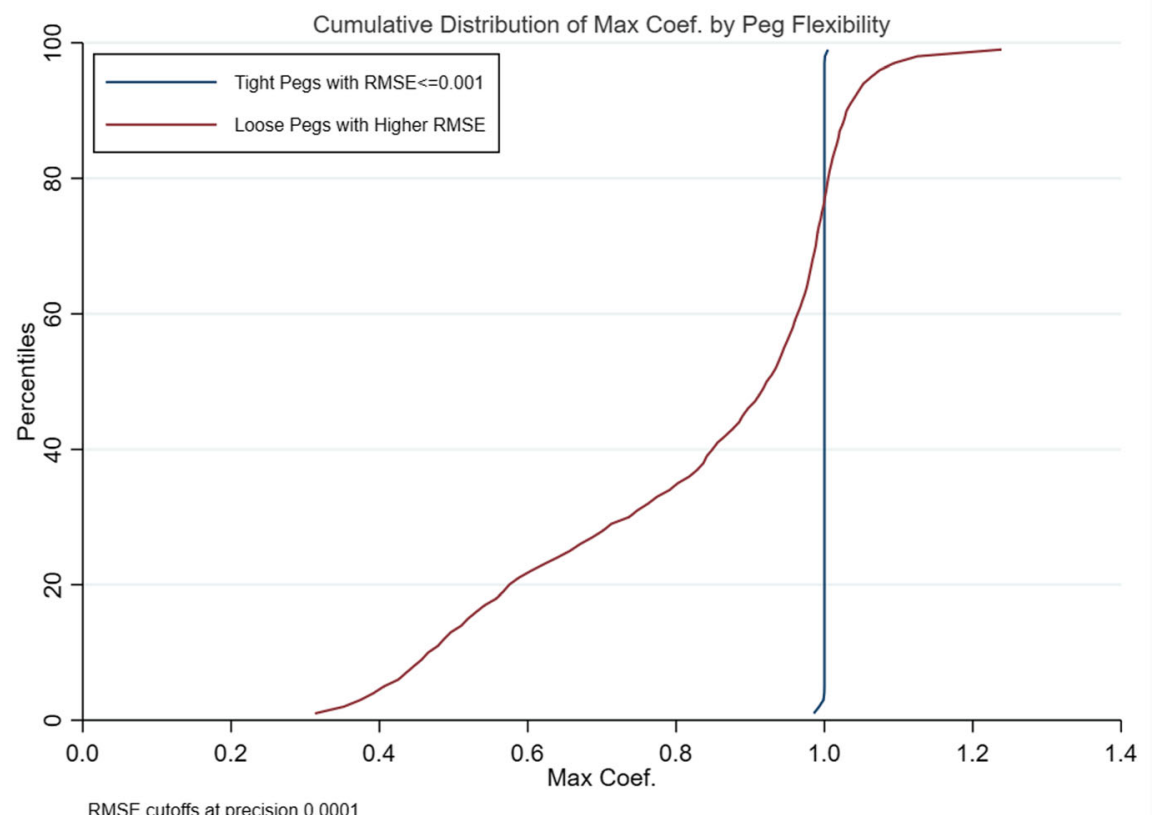

Fig. 1 The cumulative distribution of the largest exchange rate coefficient for pegs. Note: based on 24-month regressions

float without intervention to manage the exchange rate), but an alternative interpretation might be that pegs do not have EMP ratios as low as expected for the reasons given above. Ahmad and Pentecost (2020) examine a relatively small sample of eight African countries from 1970 to 2019 and use a similar statistical approach, based on the proportion of monthly exchange rate and reserve movements that exceed a certain threshold $( \pm 1 \%$ or $\pm 2.5 \%)$. They find that the proportion of the time that the exchange rate movement exceeds either of these thresholds is similar between pegged and floating regimes, but that reserve movements exceed the thresholds more often, not less often, under floating, which seems in direct contradiction to the predictions of EMP theory.

In this study, we use a large cross-country sample of monthly data between 1980 and 2019 to investigate the relationship between exchange rate flexibility and reserve variability.

We first take a look inside the regressions used to generate our measure of exchange rate flexibility. If we imagine a government whose policy is to keep its currency (the peso) within a certain band of $\pm x \%$ about a fixed central rate to the US dollar, then in our regressions the fitted value of the log change in pesos per yen will equal the log change in dollars per yen, and the residual will represent a depreciation in the peso relative to its central rate against the dollar. If the government is intervening in the foreign exchange market, that will be reflected in the change in reserves. The theory of EMP predicts that intervention to keep the exchange rate within the $\pm x \%$ band will tend to take the form of sales of foreign currency when the exchange rate is depreciating within the band and purchases when it is appreciating. We therefore investigate the 
correlation between the residuals in each month of the regression and the change in the $\log$ of reserves. For each country-year observation this generates a correlation coefficient which, according to EMP theory, should be negative when the authorities are intervening to stabilise the exchange rate (since a depreciation is represented by a positive residual). We investigate the distribution of this correlation coefficient for all observations other than tight pegs, which are excluded because the exchange rate variation is too small. The data on reserves are from IMF Financial Statistics and exclude gold. They are denominated in US dollars. Excluding gold takes out the effects of fluctuations in the price of gold, which would change total reserves without representing any intervention in the foreign exchange market. Excluding gold does however misrepresent intervention in months where gold is bought or sold in exchange for foreign exchange reserves, as happens occasionally.

Table 2 gives some data about the distribution of this correlation across the whole sample (excluding tight pegs), for the 12-month, 18-month and 24-month regressions and for different ranges of exchange rate flexibility. The mean and the median correlations are -0.078 and -0.087 respectively for the 12 -month regressions, -0.079 and -0.088 for the 18 -month regressions, and -0.084 and -0.090 respectively for the 24-month regressions. These numbers are all significantly different from zero, so there is evidence of the expected negative correlation, although the percentiles indicate that

Table 2 Correlation between exchange rate depreciation and reserve accumulation

\begin{tabular}{|c|c|c|c|c|c|c|c|c|c|}
\hline \multicolumn{10}{|l|}{ 12-Month Window } \\
\hline & count & mean & $\min$ & $\max$ & p10 & p25 & p50 & p75 & p90 \\
\hline $0.001 \leq \mathrm{RMSE}<0.01$ & 2032 & -0.058 & -0.958 & 0.945 & -0.440 & -0.268 & -0.062 & 0.149 & 0.343 \\
\hline $0.01 \leq \mathrm{RMSE}<0.02$ & 936 & -0.105 & -0.930 & 0.926 & -0.493 & -0.323 & -0.123 & 0.093 & 0.310 \\
\hline RMSE $>0.02$ & 979 & -0.092 & -0.944 & 0.926 & -0.546 & -0.335 & -0.104 & 0.135 & 0.364 \\
\hline Total (RMSE $\geq 0.001)$ & 3947 & -0.078 & -0.958 & 0.945 & -0.480 & -0.299 & -0.087 & 0.133 & 0.344 \\
\hline \multicolumn{10}{|l|}{ 18-Month Window } \\
\hline & count & mean & $\min$ & $\max$ & p10 & $\mathrm{p} 25$ & p50 & p75 & p90 \\
\hline $0.001 \leq \mathrm{RMSE}<0.01$ & 1933 & -0.064 & -0.960 & 0.678 & -0.382 & -0.235 & -0.069 & 0.102 & 0.258 \\
\hline $0.01 \leq \mathrm{RMSE}<0.02$ & 997 & -0.093 & -0.917 & 0.908 & -0.445 & -0.275 & -0.110 & 0.089 & 0.255 \\
\hline RMSE $>0.02$ & 1110 & -0.093 & -0.854 & 0.930 & -0.476 & -0.294 & -0.109 & 0.088 & 0.298 \\
\hline Total (RMSE $\geq 0.001)$ & 4040 & -0.079 & -0.960 & 0.930 & -0.424 & -0.257 & -0.088 & 0.095 & 0.264 \\
\hline \multicolumn{10}{|l|}{ 24-Month Window } \\
\hline & count & mean & $\min$ & $\max$ & $\mathrm{p} 10$ & p25 & p50 & p75 & p90 \\
\hline $0.001 \leq \mathrm{RMSE}<0.01$ & 1849 & -0.067 & -0.962 & 0.807 & -0.349 & -0.212 & -0.068 & 0.075 & 0.221 \\
\hline $0.01 \leq \mathrm{RMSE}<0.02$ & 1054 & -0.109 & -0.890 & 0.910 & -0.421 & -0.274 & -0.109 & 0.037 & 0.192 \\
\hline RMSE $>0.02$ & 1216 & -0.088 & -0.879 & 0.862 & -0.422 & -0.282 & -0.102 & 0.079 & 0.245 \\
\hline Total (RMSE $\geq 0.001)$ & 4119 & -0.084 & -0.962 & 0.910 & -0.387 & -0.248 & -0.090 & 0.070 & 0.225 \\
\hline
\end{tabular}

The figures in each row relate to the distribution of the correlation between the regression residual (which represents exchange rate appreciation) and the change in the log of reserves over the 12,18 or 24 months of the regression for the sample with RMSE in the range indicated for that row. The RMSE precision cut-off is 0.0001. Exchange rate: Domestic Currency Units per Numeraire Currency. For example the first row refers to the 2032 12-month regressions where the RMSE was between 0.001 and 0.01 . The cases of RMSE $<0.001$ are omitted because the residuals are too small. p10, p25 ..: 10th, 25 th, ... percentile of the correlation coefficient. Mean and median are shown in bold 
the correlation is negative in only about two-thirds of cases, and this tends to be true over the whole range of RMSE. Moreover one might expect the correlations to be more negative at the less flexible end of the spectrum, where EMP theory would predict that intervention would be more intense. This is not the case, however. The correlations are always less negative, not more negative, on average for pegs (RMSE <0.01) than for RMSE $\geq 0.01$, and the difference is highly statistically significant (the median is between -0.06 and -0.07 for Loose Pegs, and between -0.10 and -0.11 for floats). This is consistent with the argument that credible pegs need little intervention to keep the exchange rate within the announced range.

Next we turn to the question of the relationship between the variability of exchange rates and of reserves. The issue is whether the standard deviation of the log of reserves over a given period varies negatively and systematically with the degree of exchange rate flexibility over the same period, as EMP theory suggests. If there is less exchange rate flexibility, does there tend to be more reserve variability, either across the whole spectrum of regimes or, as we have suggested, perhaps only at the more flexible end of the spectrum?

Table 3 provides some relevant statistics. Results for 12-month, 18-month and 24month regressions are all shown, but they all present a similar picture. Using the 24month regression results (the last row in each panel of Table 3), we can see that there is not a monotonic relationship between exchange rate flexibility and the standard

Table 3 Distribution of the standard deviation of the log of reserves

\begin{tabular}{|c|c|c|c|c|c|c|c|c|c|}
\hline & count & mean & $\min$ & Max & p10 & $\mathrm{p} 25$ & p50 & p75 & p90 \\
\hline \multicolumn{10}{|l|}{ RMSE $<0.001$} \\
\hline $12 \mathrm{~m}$-Window & 2359 & 0.095 & 0.000 & 0.526 & 0.022 & 0.039 & 0.066 & 0.113 & 0.201 \\
\hline $18 \mathrm{~m}$-Window & 2293 & 0.095 & 0.000 & 0.524 & 0.024 & 0.041 & 0.067 & 0.114 & 0.197 \\
\hline $24 \mathrm{~m}$-Window & 2236 & 0.099 & 0.000 & 0.528 & 0.026 & 0.044 & 0.071 & 0.117 & 0.208 \\
\hline \multicolumn{10}{|c|}{$0.001 \leq \mathrm{RMSE}<0.01$} \\
\hline $12 \mathrm{~m}$-Window & 2022 & 0.078 & 0.000 & 0.520 & 0.019 & 0.032 & 0.055 & 0.092 & 0.167 \\
\hline $18 \mathrm{~m}$-Window & 1922 & 0.079 & 0.000 & 0.529 & 0.021 & 0.034 & 0.056 & 0.092 & 0.166 \\
\hline $24 \mathrm{~m}$-Window & 1840 & 0.081 & 0.002 & 0.528 & 0.022 & 0.035 & 0.058 & 0.095 & 0.163 \\
\hline \multicolumn{10}{|c|}{$0.01 \leq \mathrm{RMSE}<0.02$} \\
\hline $12 \mathrm{~m}$-Window & 930 & 0.066 & 0.003 & 0.448 & 0.015 & 0.024 & 0.045 & 0.079 & 0.137 \\
\hline $18 \mathrm{~m}$-Window & 991 & 0.070 & 0.003 & 0.422 & 0.016 & 0.026 & 0.049 & 0.088 & 0.149 \\
\hline $24 \mathrm{~m}$-Window & 1046 & 0.071 & 0.003 & 0.507 & 0.018 & 0.029 & 0.054 & 0.089 & 0.146 \\
\hline \multicolumn{10}{|l|}{ RMSE $>0.02$} \\
\hline $12 \mathrm{~m}$-Window & 966 & 0.096 & 0.000 & 0.518 & 0.018 & 0.032 & 0.060 & 0.122 & 0.231 \\
\hline $18 \mathrm{~m}$-Window & 1095 & 0.100 & 0.000 & 0.533 & 0.020 & 0.033 & 0.063 & 0.131 & 0.229 \\
\hline $24 \mathrm{~m}$-Window & 1194 & 0.106 & 0.002 & 0.531 & 0.021 & 0.036 & 0.070 & 0.147 & 0.250 \\
\hline \multicolumn{10}{|l|}{ Whole sample } \\
\hline 12-Window & 6277 & 0.085 & 0.000 & 0.526 & 0.019 & 0.033 & 0.058 & 0.104 & 0.188 \\
\hline 18-Window & 6301 & 0.087 & 0.000 & 0.533 & 0.020 & 0.035 & 0.060 & 0.106 & 0.189 \\
\hline 24-Window & 6316 & 0.091 & 0.000 & 0.531 & 0.021 & 0.037 & 0.063 & 0.110 & 0.195 \\
\hline
\end{tabular}

Both RMSE and the standard deviation of the log of reserves are trimmed by $2 \%$ at the top end. "p 10 " is the tenth percentile 
deviation of reserve changes. For RMSE $<0.001$, the median reserve variability is 0.071 , which is higher than for RMSE in the range 0.001 to $0.01(0.058)$ or 0.01 to $0.02(0.054)$, but very similar to RMSE greater than $0.02(0.070)$. The picture is much the same for 12-month and 18-month regressions.

Before discussing this further, it is useful to construct a measure of EMP as the standardised sum of exchange rate flexibility and reserve variability, and to investigate the distribution of this variable as well as the relationship between its two components. We compare the flexibility index described in Section Two, which was based purely on exchange rates, to a flexibility index based on the ratio of the two components of EMP.

We construct a bivariate index of exchange rate flexibility in country $j$ in year $t$ $\left(B F L E X_{j t}\right)$, after normalising the variables to have the same standard deviation over the whole sample, as follows. Define $\operatorname{EMP}\left(E M P_{j t}\right)$ as the sum of $Z E_{j t}$ and $Z R_{j t}$, where $Z E_{j t}$ is 100 times the RMSE and $Z R_{j t}$ is 100 times the standard deviation of the log of reserves (SDR), multiplied by the ratio of the sample standard deviation of RMSE $(Y)$ to the sample standard deviation of SDR $(X)$ (both $2 \%$ trimmed at the upper end):

$$
E M \mathrm{P}_{j t}=Z E_{j t}+Z R_{j t}=100 * R M S E_{j t}+100 *\left(\frac{Y}{X}\right) S D R_{j t}
$$

In this case the value of $Y$ is 0.018 and of $X$ is 0.087 , so the standardisation coefficient 0.211 . Eq. (1) keeps the minimum possible value of EMP at zero. The bivariate index of flexibility is the percentage of EMP represented by ZE rather than by ZR, or in other words how much of EMP variability can be attributed to exchange rates rather than reserves:

$$
B F L E X_{j t}=\left(\frac{Z E}{E M P V A R}\right)_{j t}
$$

Table 4 presents some data about EMP and BFLEX in relation to different degrees of exchange rate variability. EMP is only slightly larger for RMSE between 0.001 and 0.01 than for RMSE $<0.001$ (2.23 compared with 2.10 using the 24-month regression window), but jumps to 2.97 for RMSE between 0.01 and 0.02 , and then more than doubles to 6.44 for RMSE $>0.02$. The pattern for BFLEX is rather the opposite of that, with the smallest differences between the two highest categories of RMSE. When RMSE is very small $(<0.001)$, BFLEX is also very small (1.0\% using a 24 -month window), so there is very little difference between them for tight pegs. The average of BFLEX for looser pegs (RMSE between 0.001 and 0.01 ) is $29.6 \%$, rising to $55.9 \%$ for RMSE between 0.01 and 0.02 and $68.6 \%$ for RMSE over 0.02 .

Table 5 shows the correlation between RMSE and BFLEX across the sample. The correlation is very similar whatever the length of the regression window, and is 0.66 for the whole sample (using the 24-month figure). Within the category of loose pegs (RMSE between 0.001 and 0.01 ) it is still quite high, at 0.53 , but it falls to 0.24 for RMSE in the range 0.01 to 0.02 , and to only 0.15 for RMSE above 0.02 . In tight pegs, where RMSE is very close to zero, the correlation is only 0.32 . The relatively high value for the whole sample reflects the fact that if RMSE is very small, so is BFLEX, as Table 4 shows.

By regressing $\mathrm{ZR}$ on $\mathrm{ZE}$ in a quantile regression, we can examine the relationship between reserve variability and exchange rate flexibility across the whole spectrum of 
Table 4 EMP and a bivariate exchange rate flexibility index

\begin{tabular}{lll}
\hline & EMP & Exchange rate \% of EMP \\
\hline & & $($ BFLEX) \\
12 m-Window & 1.803 & 1.251 \\
1: RMSE $<0.001$ & 1.982 & 32.281 \\
2: $0.001<=$ RMSE $<0.01$ & 2.702 & 60.700 \\
3: $0.01<=$ RMSE $<0.02$ & 5.879 & 72.041 \\
4: RMSE $>0.02$ & & \\
18 m-Window & 1.938 & 1.122 \\
1: RMSE $<0.001$ & 2.124 & 30.822 \\
2: $0.001<=$ RMSE $<0.01$ & 2.859 & 57.396 \\
3: $0.01<=$ RMSE $<0.02$ & 6.135 & 70.224 \\
4: RMSE $>0.02$ & & \\
24 m-Window & 2.102 & 1.041 \\
1: RMSE $<0.001$ & 2.233 & 29.553 \\
2: $0.001<=$ RMSE $<0.01$ & 2.965 & 55.902 \\
3: $0.01<=$ RMSE $<0.02$ & 6.438 & 68.554 \\
4: RMSE $>0.02$ &
\end{tabular}

Mean values are shown. $\mathrm{EMP}=100 *[\mathrm{RMSE}+\mathrm{a} * \mathrm{SD}($ dlnReserves $)]$, where $\mathrm{a}=$ standardisation coefficient. BFLEX $=10000 *$ RMSE $/($ EMP $)$

RMSE. Using the data from the 24-month regressions, Fig. 2 shows the point estimates of the coefficient at each decile of the distribution of RMSE, together with a $95 \%$ confidence interval (the shaded area); the OLS coefficient of 0.133 , which has a $t$ statistic of 4.77, is shown as a horizontal line. The point estimate in Fig. 2 increases steadily from effectively zero at the first decile to 0.3 at the ninth decile, and the coefficient is significantly different from zero from the third decile upwards. ${ }^{5}$

Thus the picture we get is that there is no negative correlation between reserve variability and exchange rate flexibility in pegged exchange rates, and a positive correlation in more flexible regimes.

Finally, there is the question of whether BFLEX is a superior measure of exchange rate flexibility to RMSE. There is no straightforward way to address this question. We might compare them in some way with other exchange rate classification schemes, such as those of Klein and Shambaugh (2010) or Ilzetzki et al. (2017), and interpret greater agreement as greater accuracy, but to the extent that these other schemes are based on a statistical algorithm (as they essentially are), a greater degree of agreement would simply mean greater similarity between the algorithms applied, and not necessarily greater accuracy. There is a stronger case for treating the IMF de facto classification scheme as some sort of arbiter, since that is based on the judgement of informed observers at the time (according to guidelines that are similar for all countries) and is not

\footnotetext{
${ }_{5}^{5}$ The graphs for the 18-month and 12-month regressions are similar. The actual quantile regressions are reported in the Appendix.
} 
Table 5 Correlation between RMSE and BFLEX

\begin{tabular}{llll}
\hline Regression length: & 12 months & 18 months & 24 months \\
\hline Whole sample & 0.671 & 0.667 & 0.661 \\
RMSE $<0.001$ & 0.361 & 0.351 & 0.324 \\
$0.001 \leq$ RMSE $<0.01$ & 0.525 & 0.528 & 0.538 \\
$0.01 \leq$ RMSE $<0.02$ & 0.246 & 0.223 & 0.245 \\
RMSE $\geq 0.02$ & 0.147 & 0.139 & 0.149 \\
\hline
\end{tabular}

purely statistical, and also distinguishes between managed and free floats. Moreover it does take reserve movements into account, at least in deciding whether to classify a float as a free float or a managed one. The criteria for identifying a free float in the IMF classification have been clarified in recent years, having up to 2008 essentially relied on judgement (Habermeier et al. 2009). ${ }^{6}$

Of course in comparing the IMF classification with our flexibility measures, we are comparing a system of aggregating regimes into a small number of categories with a continuous measure. The procedure that we adopt is to examine how the different categories in the IMF classification are distributed across the flexibility indices.

The results are shown in Table 6. The top half of the table refers to RMSE and the bottom half to BFLEX; for each measure Table 6 shows, first, the count of the number of (a) IMF pegs and bands and (b) IMF floats of that appear in each decile of the distribution of RMSE and BFLEX, using the 24-month window results; and then similar information for a further disaggregation of the IMF classification.

Pegs represent $67.0 \%$ of the IMF sample, managed floats $22.6 \%$ and free floats $10.4 \%$. Using the $24-$ month regressions, we find that $89.8 \%$ and $89.6 \%$ respectively of IMF pegs fall below the 60th percentile of RMSE and BFLEX. Moving up to the 70th percentile, these percentages fall to 84.5 and $84.4 \%$ respectively. This is a relatively high degree of agreement with the IMF classification, compared with that between other pairs of classification schemes, as shown for example in Eichengreen and RazoGarcia (2013) and Bleaney et al. (2017). ${ }^{7}$ The similarity of the numbers for RMSE and BFLEX suggests that there is no advantage in using information on reserve variability to identify exchange rate pegs. Above the 70th percentile, where both RMSE and BFLEX suggest some type of float, there is some divergence in the distribution of IMF pegs: for RMSE, 162 out of $3858(4.2 \%)$ appear in the highest decile, whereas for BFLEX the figure is 97 out of 3858 (2.5\%). Since the proportion of pegs above the

\footnotetext{
${ }^{6}$ The new system is described as follows in Habermeier et al. (2009, p. 8): "As noted, once a de facto exchange rate arrangement has been identified as floating, it can be further qualified as free floating if there has been no intervention over the past six months, with the exception of limited intervention to address disorderly market conditions. If IMF staff responsible for the classification do not have sufficient information and data to verify whether this criterion has been met, the arrangement is classified as floating. Data and its availability, rather than subjective judgment, thus play the key role in assigning a country to the free floating category." ${ }^{7}$ Levy-Yeyati and Sturzenegger (2016) report an agreement rate of $62.7 \%$ with the IMF de facto classification over the period 1974-2013, using three categories: fixed, intermediate and floating.
} 


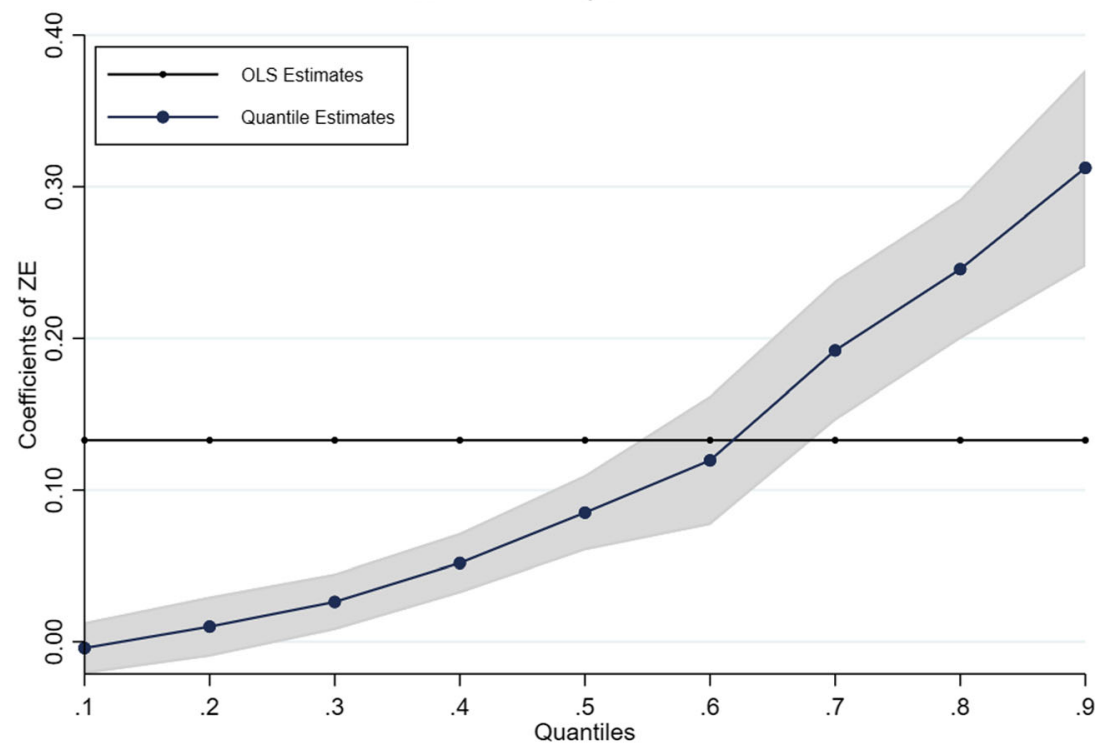

Coefficnets from simultaneous-quantile regression results. Standard errors are bootstrapped with 500 replications

Fig. 2 Quantile regression results of ZR on ZE (24-month regressions)

70th percentile is virtually identical for RMSE and BFLEX, more pegs appear in the 80th and 90th percentiles for BFLEX than for RMSE.

On the other hand, neither flexibility index seems particularly good at separating free floats from managed floats. Of IMF free floats, only 141 out of $597(23.6 \%)$ appear in the top decile of RMSE, and $198(33.2 \%)$ in the top decile of BFLEX. Clearly, BFLEX is somewhat better at picking up free floats (although if we take the top two deciles instead of just the top one, RMSE scores $351(58.8 \%)$ and BFLEX $346(58.0 \%)$ ). The other $40+\%$ of IMF free floats are spread further down the distribution, with $28(4.7 \%)$ for RMSE and $48(8.2 \%)$ for BFLEX even below the 60th percentile. Thus free floats tend to be higher up the ranking than managed floats in BFLEX as opposed to RMSE. Both measures have the problem that the natural variation of a freely floating exchange rate differs across countries, being particularly large for countries with low ratios of trade to GDP, which reflects features such as country size, population density, remoteness from trading partners and landlockedness as well as trade policy (Bleaney and Francisco 2010; Bravo-Ortega and di Giovanni 2006).

It is interesting to compare the frequency with which countries appear in the top decile of the two flexibility indices. The top half of Table 7 lists the countries which appear in the top decile of BFLEX in at least seven years more than in the top decile of RMSE, and the bottom half lists the countries which appear in the top decile of RMSE in at least seven years more than in the top decile of BFLEX. 
Table 6 Count of IMF Exchange Rate Regimes, by RMSE and BFLEX Deciles (24-month windows)

\begin{tabular}{llllllllllll}
\hline Percentile: & 10 & 20 & 30 & 40 & 50 & 60 & 70 & 80 & 90 & 100 & Total \\
\hline \multicolumn{2}{l}{ Flexibility measure: RMSE } & & & & & & & & \\
All Pegs & 574 & 568 & 559 & 529 & 463 & 412 & 301 & 167 & 123 & 162 & 3858 \\
All Floats & 3 & 9 & 16 & 47 & 113 & 164 & 275 & 409 & 453 & 414 & 1903 \\
Hard Pegs & 251 & 292 & 287 & 73 & 18 & 6 & 10 & 1 & 0 & 3 & 941 \\
Conv'l Pegs & 322 & 275 & 272 & 307 & 244 & 201 & 138 & 57 & 71 & 84 & 1971 \\
Other Pegs & 1 & 1 & 0 & 149 & 201 & 205 & 153 & 109 & 52 & 75 & 946 \\
Man'd Floats & 3 & 8 & 15 & 46 & 106 & 146 & 198 & 268 & 243 & 273 & 1306 \\
Free Floats & 0 & 1 & 1 & 1 & 7 & 18 & 77 & 141 & 210 & 141 & 597 \\
Total & 577 & 577 & 575 & 576 & 576 & 576 & 576 & 576 & 576 & 576 & 5761 \\
Flexibility measure: BFLEX & & & & & & & & & \\
All Pegs & 572 & 564 & 566 & 503 & 479 & 414 & 309 & 201 & 153 & 97 & 3858 \\
All Floats & 5 & 12 & 10 & 73 & 97 & 162 & 267 & 375 & 423 & 479 & 1903 \\
Hard Pegs & 245 & 312 & 281 & 51 & 18 & 16 & 10 & 5 & 3 & 0 & 941 \\
Conv'l Pegs & 326 & 252 & 284 & 278 & 258 & 205 & 161 & 82 & 70 & 55 & 1971 \\
Other Pegs & 1 & 0 & 1 & 174 & 203 & 193 & 138 & 114 & 80 & 42 & 946 \\
Man'd Floats & 5 & 12 & 8 & 72 & 81 & 132 & 192 & 252 & 275 & 281 & 1306 \\
Free Floats & 0 & 0 & 2 & 1 & 16 & 30 & 75 & 123 & 148 & 198 & 597 \\
Total & 577 & 576 & 576 & 576 & 576 & 576 & 576 & 576 & 576 & 576 & 5761 \\
\hline
\end{tabular}

The categories are based on the IMF de facto classification, for details of which see Habermeier et al. (2009). Hard peg: no separate legal tender or currency board arrangement. Conventional peg: peg to a single currency or basket, not necessarily announced, with a deviation from central rate of less than $\pm 1 \%$ over six months. Other peg: either a crawling peg, or a horizontal peg with deviation from central rate of $\pm 1 \%$ or more over six months. Free Float: a floating currency with only occasional intervention in the foreign exchange market. Managed Float: the residual category

There is a distinct difference between the two lists. High-income and middle-income countries appear more frequently in the top decile of BFLEX, with the United States (29 years compared to 6) and Japan (33 years compared to 5) being especially prominent. Developing countries appear more frequently in the top decile of RMSE, with sub-Saharan African countries making up eight of the thirteen in the bottom half of Table 7. This suggests that there is much more intervention in the foreign exchange market amongst floating currencies in the latter group of countries, and that the former group are much closer to an independent float.

Although Fig. 2 shows a positive correlation between exchange rate flexibility and reserve volatility throughout the distribution, it is possible that the negative correlation posited by EMP theory would emerge if we controlled for the "natural" variation of different currencies that would be observed if they were all freely floating. Accordingly Table 8 shows the results of a regression of 12-month exchange rate flexibility on reserve volatility, per capita GDP relative to the United States, inflation, trade openness and land area per capita (a proxy for likely specialisation in commodity exports). Per capita GDP is either at PPP (columns 1 and 3) or in constant US\$ (columns 2 and 4), which is available for a slightly 
Table 7 Frequency of countries' appearance in the top deciles of RMSE and BFLEX

\begin{tabular}{|c|c|c|}
\hline & \multicolumn{2}{|c|}{$\begin{array}{l}\text { Appearance in top decile of BFLEX 7+ times more frequently than in top decile of } \\
\text { RMSE }\end{array}$} \\
\hline Country & RMSE frequency & BFLEX frequency \\
\hline United States & 6 & 29 \\
\hline United Kingdom & 0 & 9 \\
\hline Canada & 2 & 17 \\
\hline Japan & 5 & 33 \\
\hline Turkey & 11 & 19 \\
\hline Chile & 6 & 19 \\
\hline Colombia & 8 & 21 \\
\hline India & 2 & 9 \\
\hline Nepal & 0 & 8 \\
\hline Iraq & 1 & 12 \\
\hline Israel & 6 & 20 \\
\hline Indonesia & 6 & 16 \\
\hline Singapore & 0 & 11 \\
\hline South Korea & 5 & 20 \\
\hline Thailand & 3 & 14 \\
\hline \multirow[t]{2}{*}{ Poland } & 6 & 14 \\
\hline & \multicolumn{2}{|c|}{ Appearance in top decile of BFLEX 7+ times less frequently than in top decile of RMSE } \\
\hline Country & RMSE frequency & BFLEX frequency \\
\hline Iceland & 10 & 3 \\
\hline New Zealand & 10 & 2 \\
\hline Argentina & 12 & 5 \\
\hline Dem. Rep. Congo & 15 & 2 \\
\hline Ghana & 10 & 3 \\
\hline Guinea & 8 & 0 \\
\hline Malawi & 16 & 0 \\
\hline Nigeria & 8 & 1 \\
\hline Sierra Leone & 11 & 0 \\
\hline Tanzania & 8 & 1 \\
\hline Zambia & 16 & 6 \\
\hline Papua New Guinea & 8 & 0 \\
\hline Romania & 10 & 3 \\
\hline
\end{tabular}

Based on 24-month regressions. The table shows the number of years between 1980 and 2018 that the country appears in the top decile of the flexibility index indicated. RMSE -exchange rate flexibility index; BFLEX flexibility index based on exchange rate and reserve variability. Countries are listed in order of IFS code

larger sample. Columns 1 and 2 are pooled OLS regressions, and the main features are that exchange rate flexibility increases with inflation and decreases with trade openness and per capita GDP. For completeness, Columns 3 and 4 show the same regressions with year and country dummies; not surprisingly the variables that have 
Table 8 Explaining exchange rate flexibility for floating currencies

\begin{tabular}{|c|c|c|c|c|}
\hline \multirow[t]{4}{*}{ Dependent variable: } & \multicolumn{4}{|c|}{ 12-month exchange rate flexibility (ZE) } \\
\hline & (1) & (2) & (3) & (4) \\
\hline & OLS & OLS & $\mathrm{FE}$ & $\mathrm{FE}$ \\
\hline & $\begin{array}{l}\text { GDPpc } \\
\text { PPP }\end{array}$ & $\begin{array}{l}\text { GDPpc } \\
\text { Constant USD }\end{array}$ & $\begin{array}{l}\text { GDPpc } \\
\text { PPP }\end{array}$ & $\begin{array}{l}\text { GDPpc } \\
\text { Constant USD }\end{array}$ \\
\hline \multirow[t]{2}{*}{ ZR } & $0.179 *$ & $0.160 * *$ & $0.226 * *$ & $0.183^{* *}$ \\
\hline & $(1.87)$ & $(2.15)$ & $(2.27)$ & $(2.20)$ \\
\hline \multirow[t]{2}{*}{ GDPpc } & -0.010 & $-0.005^{* *}$ & -0.019 & -0.004 \\
\hline & $(-1.60)$ & $(-2.27)$ & $(-0.67)$ & $(-0.39)$ \\
\hline \multirow[t]{2}{*}{ CPI Inflation (\%) } & $0.053 * * *$ & $0.052 * * *$ & $0.070 * * *$ & $0.072 * * *$ \\
\hline & $(3.96)$ & $(3.93)$ & $(5.05)$ & $(5.34)$ \\
\hline \multirow[t]{2}{*}{ Trade Openness } & $-0.414 * * *$ & $-0.419 * * *$ & -0.311 & -0.288 \\
\hline & $(-2.85)$ & $(-3.17)$ & $(-0.72)$ & $(-0.68)$ \\
\hline \multirow[t]{2}{*}{ Ln (Land area pc) } & -0.031 & -0.055 & -5.288 & -4.032 \\
\hline & $(-0.05)$ & $(-0.09)$ & $(-1.44)$ & $(-0.83)$ \\
\hline \multirow[t]{2}{*}{ Constant } & $1.861 * * *$ & $1.898 * * *$ & $1.390 * *$ & 0.600 \\
\hline & $(9.33)$ & $(10.39)$ & $(2.08)$ & $(0.74)$ \\
\hline Country Dummies & No & No & Yes & Yes \\
\hline Year Dummies & No & No & Yes & Yes \\
\hline No. of Countries & 96 & 97 & 96 & 97 \\
\hline Observations & 1539 & 1639 & 1539 & 1639 \\
\hline R-squared & 0.09 & 0.09 & 0.15 & 0.15 \\
\hline RMSE & 1.667 & 1.679 & 1.407 & 1.435 \\
\hline
\end{tabular}

The dependent variable is 12 -month exchange rate flexibility (ZE). Sample: all floats identified by the IMF de facto classification 1980-2019. Country-years with consumer price inflation $>40 \%$ omitted. Standard errors are clustered at the country level. The numbers in parentheses are t-statistics. $* * *, * * * *$ coefficient significantly different from zero at 1,5 and 10\% respectively. ZR: normalised 12-month reserve volatility. GDP per capita is ratio of US GDP per capita in same year. Trade openness: (exports + imports)/GDP

relatively little time variation within each country (trade openness, per capita GDP) lose their statistical significance. The important point, however, is that the coefficient of the reserve volatility variable is still significantly positive, contrary to the predictions of EMP theory.

\section{Conclusions}

Most currencies are managed to some degree. The argument that exchange rate classifications should be based on exchange rate flexibility relative to reserve variability therefore has a natural appeal, because it captures to what degree the exchange rate is being managed by intervention. However, there are some significant problems in using this "EMP ratio" to identify exchange rate pegs and bands. The marginal cost of exchange rate variability suddenly becomes 
very large at a certain threshold that represents movement outside the announced band, because the concept implicitly assumes continuity in the marginal cost of the two components of the EMP ratio, and there is a sharp discontinuity in the marginal cost of exchange rate flexibility at the boundary of the peg. This creates a clustering of observations with similarly low exchange rate flexibility but considerable variation in reserve volatility, thus making the EMP ratio rather uninformative. This drawback does not apply to the issue of distinguishing more from less tightly managed floats, since the assumed continuity of marginal cost is likely to hold. This implies that the EMP ratio may be more useful in identifying how tightly managed a float is than in identifying a peg.

There has been relatively little research on the behaviour of reserves in relation to exchange rate movements. We have investigated the issue for a global sample of countries from 1980 to 2019. First of all we investigated whether month-to-month reserve accumulation is negatively correlated with exchange rate depreciation, as would be expected if reserves were being used for the purpose of exchange rate stabilisation. It turns out that this is the case in a comfortable majority of country-years (about two-thirds). On the other hand, the correlation is weaker rather than stronger for the least flexible regimes, contrary to what might be expected.

We then examined the relationship between the variabilities of exchange rates and reserves over periods of 12,18 and 24 months, and found that the correlation tends to be positive rather than negative, particularly at the more flexible end of the spectrum. So regimes with more stable exchange rates do not tend to have greater variability of international reserves. In all exchange rate regimes, the distribution of 12-month reserve volatility is highly skewed, with a long upper tail. Finally we constructed a flexibility index as the ratio of exchange rate flexibility to the sum of exchange rate flexibility and standardised reserve variability, and investigated whether this bivariate flexibility index matched the IMF de facto regime classification better than the exchange rate flexibility component alone. With respect to the splits between pegs or bands and some type of floating, taking reserves into account made very little difference: nearly $90 \%$ of IMF pegs (which represent about twothirds of the sample) lie below the 60th percentile of either flexibility index. This finding supports the view that reserve volatility does not add any useful information for identifying a peg.

However, regimes classed by the IMF as free floats rather than managed ones (just over $10 \%$ of the sample) were more likely to be in the top $10 \%$ of the bivariate flexibility index than in the top $10 \%$ of one based purely on exchange rates, which suggests that a lack of reserve variability helps to identify freely floating currencies. This is consistent with the idea that the EMP ratio adds value as an indicator of the extent to which a float is managed. On the other hand, when we estimated a model of the volatility of floating exchange rates as a function of control variables such as inflation and trade openness, to test whether greater reserve volatility was negatively correlated with exchange rate flexibility after controlling for an economy's "natural" exchange rate volatility, the coefficient of reserve volatility remained significantly positive, rather than negative as predicted in the EMP approach. 


\section{Appendix}

Table 9 Maximum exchange rate coefficient for Tight and Loose Pegs

\begin{tabular}{|c|c|c|c|c|c|c|c|c|c|}
\hline \multicolumn{10}{|c|}{ 12-Month Window } \\
\hline & count & mean & $\min$ & $\max$ & $\mathrm{p} 10$ & $\mathrm{p} 25$ & $\mathrm{p} 50$ & p75 & p90 \\
\hline Tight Peg & 1955 & 0.995 & 0.283 & 1.204 & 1.000 & 1.000 & 1.000 & 1.000 & 1.000 \\
\hline Loose Peg & 2000 & 0.887 & 0.233 & 67.614 & 0.468 & 0.651 & 0.920 & 1.004 & 1.071 \\
\hline Total & 3955 & 0.940 & 0.233 & 67.614 & 0.572 & 0.910 & 1.000 & 1.000 & 1.021 \\
\hline \multicolumn{10}{|c|}{ 18-Month Window } \\
\hline & count & mean & $\min$ & $\max$ & p10 & $\mathrm{p} 25$ & $\mathrm{p} 50$ & p75 & p90 \\
\hline Tight Peg & 1901 & 0.997 & 0.420 & 1.038 & 1.000 & 1.000 & 1.000 & 1.000 & 1.000 \\
\hline Loose Peg & 1917 & 0.840 & 0.246 & 7.470 & 0.472 & 0.644 & 0.916 & 0.998 & 1.045 \\
\hline Total & 3818 & 0.918 & 0.246 & 7.470 & 0.577 & 0.912 & 1.000 & 1.000 & 1.009 \\
\hline \multicolumn{10}{|c|}{ 24-Month Window } \\
\hline & count & mean & $\min$ & $\max$ & $\mathrm{p} 10$ & $\mathrm{p} 25$ & $\mathrm{p} 50$ & p75 & p90 \\
\hline Tight Peg & 1846 & 0.999 & 0.419 & 1.204 & 1.000 & 1.000 & 1.000 & 1.000 & 1.000 \\
\hline Loose Peg & 1850 & 0.840 & 0.255 & 23.727 & 0.464 & 0.647 & 0.921 & 0.997 & 1.030 \\
\hline Total & 3696 & 0.919 & 0.255 & 23.727 & 0.571 & 0.918 & 1.000 & 1.000 & 1.007 \\
\hline
\end{tabular}

The table gives statistics for the distribution of the largest exchange rate coefficient in the regression for Tight Pegs (RMSE<0.001) and Loose Pegs $(0.001<=\mathrm{RMSE}<0.01)$; p10 denotes the tenth percentile of the distribution

Table 10 Distribution of BFLEX for different ranges of RMSE_trm02

\begin{tabular}{lccccccccc}
\hline & count & mean & min & max & p10 & p25 & p50 & p75 & p90 \\
\hline RMSE<0.001 & & & & & & & & & \\
12-Window & 2359 & 1.251 & 0.000 & 100.000 & 0.000 & 0.000 & 0.002 & 0.004 & 0.719 \\
18-Window & 2293 & 1.122 & 0.000 & 100.000 & 0.000 & 0.000 & 0.001 & 0.003 & 0.186 \\
24-Window & 2236 & 1.041 & 0.000 & 100.000 & 0.000 & 0.000 & 0.001 & 0.003 & 0.018 \\
0.001<=RMSE<0.01 & & & & & & & & \\
12-Window & 2022 & 32.281 & 1.456 & 100.000 & 9.931 & 17.496 & 29.427 & 44.183 & 58.985 \\
18-Window & 1922 & 30.822 & 1.339 & 100.000 & 9.901 & 16.694 & 27.947 & 42.075 & 56.170 \\
24-Window & 1840 & 29.553 & 1.612 & 94.554 & 9.804 & 16.288 & 26.441 & 39.971 & 53.799 \\
0.01<=RMSE<0.02 & & & & & & & & \\
12-Window & 930 & 60.700 & 11.974 & 96.832 & 34.382 & 46.775 & 62.432 & 75.822 & 84.255 \\
18-Window & 991 & 57.396 & 10.541 & 95.934 & 31.130 & 44.034 & 57.935 & 71.143 & 81.860 \\
24-Window & 1046 & 55.902 & 11.827 & 95.228 & 30.062 & 42.815 & 56.084 & 70.221 & 79.955 \\
RMSE>0.02 & & & & & & & & & \\
12-Window & 966 & 72.041 & 19.829 & 100.000 & 48.815 & 62.010 & 75.095 & 84.812 & 90.599 \\
18-Window & 1095 & 70.224 & 17.708 & 100.000 & 46.670 & 59.353 & 73.140 & 83.054 & 89.340 \\
24-Window & 1194 & 68.554 & 16.345 & 98.939 & 45.092 & 56.883 & 71.348 & 81.646 & 87.708 \\
Total & & & & & & & & & \\
12-Window & 6277 & 30.949 & 0.000 & 100.000 & 0.000 & 0.003 & 23.064 & 57.233 & 78.506 \\
18-Window & 6301 & 31.041 & 0.000 & 100.000 & 0.001 & 0.003 & 24.236 & 56.530 & 78.045 \\
24-Window & 6316 & 31.196 & 0.000 & 100.000 & 0.001 & 0.002 & 25.111 & 56.484 & 77.311 \\
\hline & & & & & & & & & \\
\hline
\end{tabular}

RMSE trm02: exchange rate flexibility (top 2\% trimmed); BFLEX: bivariate flexibility index (see text). "12window" denotes results using a 12-month regression window 
Table 11 Correlation between BFLEX and RMSE_trm02

\begin{tabular}{llllll}
\hline & All & RMSE $<0.001$ & $0.001<=$ RMSE $<0.01$ & $0.01<=$ RMSE $<0.02$ & RMSE $>0.02$ \\
\hline 12-Window & 0.671 & 0.361 & 0.525 & 0.246 & 0.147 \\
18-Window & 0.667 & 0.351 & 0.528 & 0.223 & 0.139 \\
24-Window & 0.661 & 0.324 & 0.538 & 0.245 & 0.149 \\
\hline
\end{tabular}

See Notes to Appendix Table 10

Table 12 Simultaneous-quantile regression for ZR on ZE Dep. Var: ZR

\begin{tabular}{|c|c|c|c|}
\hline & 12-Window & 18-Window & 24-Window \\
\hline \multicolumn{4}{|l|}{ q10 } \\
\hline \multirow[t]{2}{*}{$\mathrm{ZE}$} & & -0.000 & \\
\hline & $(-0.672)$ & $(-0.010)$ & $(-0.460)$ \\
\hline \multirow[t]{2}{*}{ _cons } & $0.368^{* * * *}$ & $0.416^{* * *}$ & $0.462 * * *$ \\
\hline & $(35.928)$ & $(37.729)$ & $(30.004)$ \\
\hline \multicolumn{4}{|l|}{ q20 } \\
\hline \multirow[t]{2}{*}{$\mathrm{ZE}$} & -0.008 & 0.004 & 0.010 \\
\hline & $(-1.150)$ & $(0.522)$ & (0.991) \\
\hline \multirow[t]{2}{*}{ _cons } & $0.545^{* * * *}$ & $0.607 * * *$ & $0.667 * * *$ \\
\hline & $(52.395)$ & $(53.645)$ & $(46.046)$ \\
\hline \multicolumn{4}{|l|}{ q30 } \\
\hline \multirow[t]{2}{*}{$\mathrm{ZE}$} & 0.006 & $0.018^{*}$ & $0.026^{* * *}$ \\
\hline & $(0.561)$ & (1.648) & (2.614) \\
\hline \multirow[t]{2}{*}{ _cons } & $0.705^{* * * *}$ & $0.781^{* * *}$ & $0.854 * * *$ \\
\hline & $(47.691)$ & $(50.280)$ & $(68.599)$ \\
\hline \multicolumn{4}{|l|}{ q40 } \\
\hline \multirow[t]{2}{*}{$\mathrm{ZE}$} & 0.013 & $0.048 * * *$ & $0.052 * * *$ \\
\hline & (1.179) & (4.588) & (4.974) \\
\hline \multirow[t]{2}{*}{ _cons } & $0.886^{* * *}$ & $0.957 * * *$ & $1.046^{* * * *}$ \\
\hline & $(52.346)$ & $(72.931)$ & $(66.321)$ \\
\hline \multicolumn{4}{|l|}{ q50 } \\
\hline \multirow[t]{2}{*}{$\mathrm{ZE}$} & $0.047 * * *$ & $0.064 * * *$ & $0.085^{* * *}$ \\
\hline & (3.660) & (5.109) & $(6.670)$ \\
\hline \multirow[t]{2}{*}{ _cons } & $1.067^{* * *}$ & $1.166^{* * *}$ & $1.250 * * *$ \\
\hline & $(68.534)$ & $(74.022)$ & $(70.028)$ \\
\hline \multicolumn{4}{|l|}{ q60 } \\
\hline \multirow[t]{2}{*}{$\mathrm{ZE}$} & $0.069 * * *$ & $0.090 * * *$ & $0.120 * * *$ \\
\hline & $(4.946)$ & $(5.568)$ & (5.308) \\
\hline \multirow[t]{2}{*}{ _cons } & $1.307 * * *$ & $1.420 * * *$ & $1.522 * * *$ \\
\hline & (68.304) & $(64.962)$ & $(62.433)$ \\
\hline
\end{tabular}


Table 12 (continued)

12-Window 24-Window

\begin{tabular}{llll}
\hline q70 & & & \\
ZE & $0.097 * * *$ & $0.142 * * *$ & $0.192 * * *$ \\
& $(4.611)$ & $(6.182)$ & $(7.895)$ \\
cons & $1.639 * * *$ & $1.763 * * *$ & $1.854 * * *$ \\
& $(57.959)$ & $(59.698)$ & $(58.014)$ \\
q80 & & & $0.246 * * *$ \\
ZE & $0.163 * * *$ & $0.215 * * *$ & $(10.854)$ \\
& $(5.857)$ & $(8.607)$ & $2.428 * * *$ \\
cons & $2.156^{* * *}$ & $2.289 * * *$ & $(52.659)$ \\
q90 & $(49.373)$ & $(48.516)$ & \\
ZE & & & $0.313 * * *$ \\
& $0.199 * * *$ & $0.273 * * *$ & $(9.159)$ \\
cons & $(4.731)$ & $(5.943)$ & $3.666^{* * *}$ \\
$\mathrm{~N}$ & $3.358^{* * * *}$ & $3.525 * * *$ & $(52.931)$ \\
\hline
\end{tabular}

$Z R$, standardised reserve variability; $Z E$, exchange rate flexibility.

$* * * * * * 10 \% 5 \% 1 \%$. Bootstrapped t-statistics in parentheses

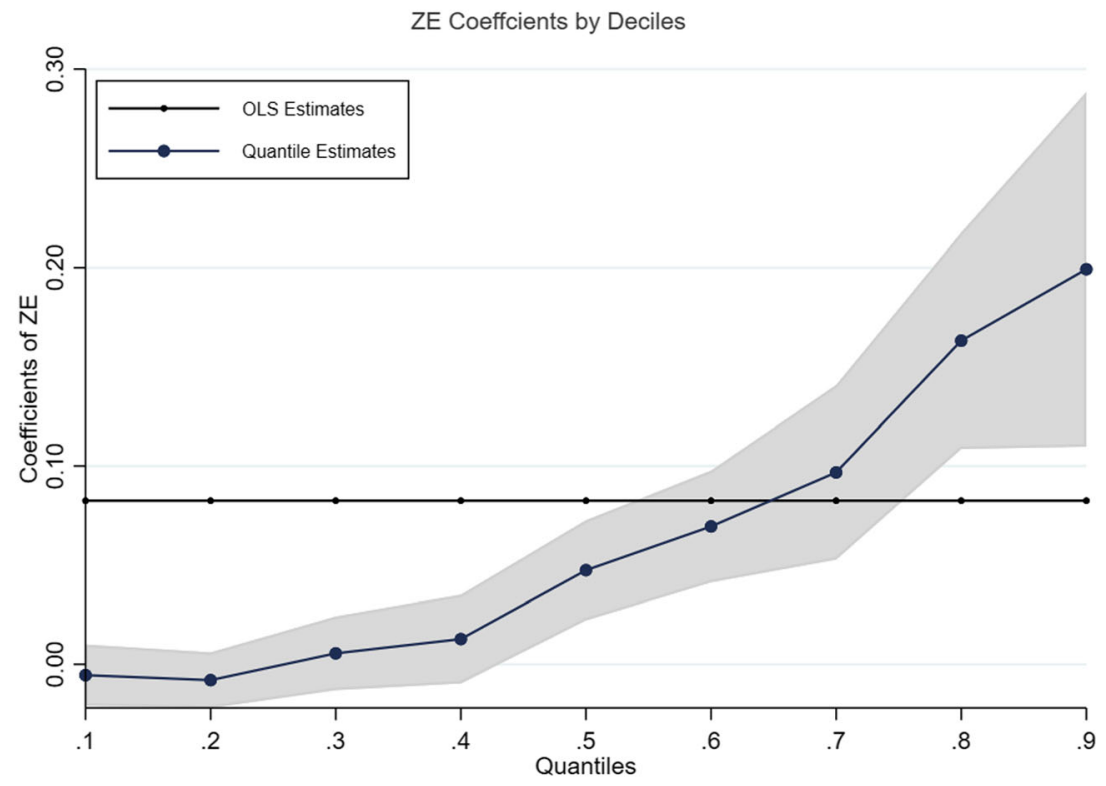

Coefficnets from simultaneous-quantile regression results. Standard errors are bootstrapped with 500 replications.

Fig. 3 Results from quantile regressions of standardised reserve variability on exchange rate flexibility using a 12-month regression window 


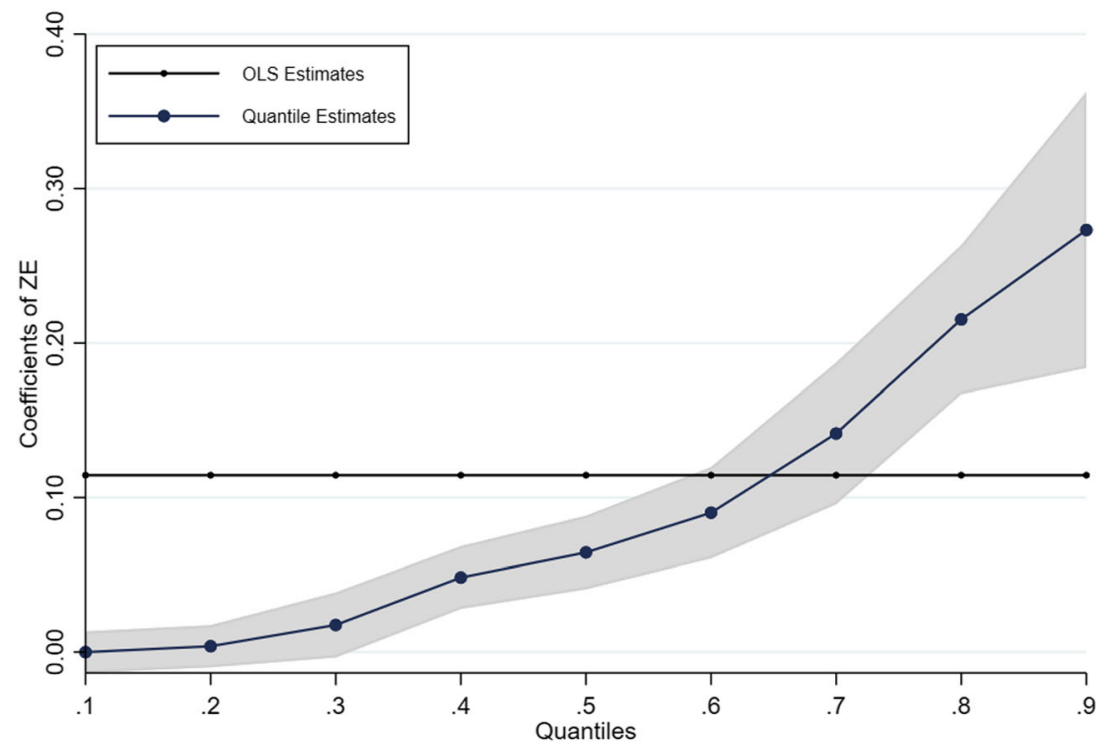

Coefficnets from simultaneous-quantile regression results. Standard errors are bootstrapped with 500 replications

Fig. 4 Results from quantile regressions of standardised reserve variability on exchange rate flexibility using an 18-month regression window

Acknowledgements The authors thank the editor, George Tavlas, and two anonymous referees for extremely helpful comments on a previous version. Any errors that remain are, of course, the authors' responsibility.

Authors' Contributions the two authors have contributed equally to this research.

Open Access This article is licensed under a Creative Commons Attribution 4.0 International License, which permits use, sharing, adaptation, distribution and reproduction in any medium or format, as long as you give appropriate credit to the original author(s) and the source, provide a link to the Creative Commons licence, and indicate if changes were made. The images or other third party material in this article are included in the article's Creative Commons licence, unless indicated otherwise in a credit line to the material. If material is not included in the article's Creative Commons licence and your intended use is not permitted by statutory regulation or exceeds the permitted use, you will need to obtain permission directly from the copyright holder. To view a copy of this licence, visit http://creativecommons.org/licenses/by/4.0/.

\section{References}

Ahmad AH, Pentecost EJ (2020) Testing the 'fear of floating' hypothesis: a statistical analysis for eight African countries. Open Econ Rev 31:407-430

Aizenman J, Binici M (2016) Exchange market pressure in OECD and emerging economies: domestic vs external factors in the old and new normal. J Int Money Financ 66:65-87

Aizenman J, Lee J, Sushko V (2012) From the great moderation to the global crisis: exchange market pressure in the 2000s. Open Econ Rev 23:597-620

Bleaney MF, Francisco M (2010) What makes currencies volatile? An empirical investigation. Open Econ Rev 21:731-750 
Bleaney MF, Tian M (2017) Measuring exchange rate flexibility by regression methods. Oxf Econ Pap 69: 301-319

Bleaney MF, Tian M (2020) Exchange rate flexibility: how should we measure it? Open Econ Rev 31:881900

Bleaney MF, Tian M, Yin L (2017) De facto exchange rate regime classifications: an evaluation. Open Econ Rev 28:369-382

Bravo-Ortega C, di Giovanni J (2006) Remoteness and real exchange rate volatility. IMF Staff Pap 53(Special Issue):115-132

Eichengreen B, Razo-Garcia R (2013) How reliable are de facto exchange rate regime classifications? Int J Financ Econ 18:216-239

Frankel J, Wei S-J (1995) Emerging currency blocs, in the international monetary system: its institutions and its future, ed. H. Genberg. Berlin, Springer

Frankel J, Wei S-J (2008) Estimation of de facto exchange rate regimes: synthesis of the techniques for inferring flexibility and basket anchors. NBER Working Paper no. 14016

Girton L, Roper D (1977) A monetary model of exchange market pressure applied to the postwar Canadian experience. Am Econ Rev 67:537-548

Habermeier K, Kokenyne A, Veyrune R, Anderson H (2009) Revised system for the classification of exchange rate arrangements. IMF Working Paper no. 09/211

Hall SG, Kenjegaliev A, Swamy PAVB, Tavlas GS (2013) Measuring currency pressures: the cases of the Japanese yen, the Chinese yuan, and the UK pound. Journal of the Japanese and International Economies 29:1-20

Ilzetzki, E, Reinhart CM, Rogoff KS (2017) Exchange rate arrangements entering the 21st century: which anchor will hold? NBER Working Paper no. 23134

Klein MW, Shambaugh JC (2010) Exchange rate regimes in the modern era. MIT Press, Cambridge, Mass

Levy-Yeyati E, Sturzenegger F (2005) Classifying exchange rate regimes: deeds versus words. European Econ Rev 49:1603-1635

Levy-Yeyati E, Sturzenegger F (2016) Classifying exchange rate regimes: fifteen years on. Working paper no. 319, Center for International Development, Harvard University

Obstfeld M, Shambaugh JC, Taylor AM (2010) Financial stability, the trilemma, and international reserves. American Economic Journal: Macroeconomics 2(2):57-94

Patnaik I, Felman J, Shah A (2017) An exchange market pressure measure for cross-country analysis. J Int Money Financ 73:62-77

Reinhart CM, Rogoff K (2004) The modern history of exchange rate arrangements: a re-interpretation. Q J Econ 119:1-48

Shambaugh J (2004) The effect of fixed exchange rates on monetary policy. Q J Econ 119(1):301-352

Slavov ST (2013) De jure versus de facto exchange rate regimes in sub-Saharan Africa. J Afr Econ 22:732756

Strelchenko I (2018) Cluster analysis of the impact of currency regime type on features of the spread of financial crises. Operations Research and Decisions 28(2):71-84

Tavlas G, Dellas H, Stockman AC (2008) The classification and performance of alternative exchange-rate systems. Eur Econ Rev 52:941-963

Weymark DN (1995) Estimating exchange market pressure and the degree of exchange market intervention for Canada. J Int Econ 39:273-295

Publisher's Note Springer Nature remains neutral with regard to jurisdictional claims in published maps and institutional affiliations. 